\title{
Is patient safety sufficient in Japan? Differences in patient safety between Japan and the United States - Learning from the United States
}

\author{
Masahiro Hirose* \\ Department of Community-based Health Policy and Quality Management, Faculty of Medicine, Shimane University, Izumo, \\ Japan
}

Received: June 9, 2016

DOI: $10.5430 /$ jha.v5n6p1
Accepted: August 9, 2016

Online Published: August 17, 2016

\begin{abstract}
In Japan, patient safety has been promoted at all levels since the 1999 landmark adverse medical event at Yokohama City University Hospital (YCUH). However, patients do not believe that health care is becoming safer. Furthermore, two university hospitals (UHs) that were designated as "advanced treatment hospitals" had their status revoked by the Health Ministry as of June 1, 2015 due to patient safety problems. The history of patient safety in Japan can be roughly divided into two terms: 1999-2009 and since 2010. In the first term, a basic patient safety system was established that included the creation of a patient safety division and an incident-reporting system from the perspective of systems error rather than individual responsibility. Additionally, many companies have promoted the improvement and development of drugs and medical devices in collaboration with health care providers. The two recent serious medical errors at UHs seemed to occur partially due to a lack of medical ethics. Unlike in the United States (US), in Japan, there is no medical license renewal system, the organizations that govern physicians are weak, and the framework of lifelong education is inadequate. Therefore, the second term involves a mindset of quality-driven patient safety. It requires health care providers and policy makers to change their mindset toward medical ethics and patient safety by learning from the US and demands a strong organization and framework to govern physicians in Japan.
\end{abstract}

Key Words: Medical ethics, Patient safety in Japan and the United States, Awareness of patient safety, Policy and actions for patient safety, Systems governing physicians

\section{INTRODUCTION}

Unlike in the United States (US) and other countries worldwide, in Japan, the term "health care safety" was used to mean "patient safety" (Japanese health care professionals officially use the phrase "health care safety" [Iryou Anzen in Japanese] to mean "patient safety" [Kanja Anzen in Japanese] under the supervision of the government, although the government's meaning is not clear). Although the term "patient safety" should be used in the sense of the Hippocratic
Oath, ${ }^{[1]}$ it is not used in this way.

After the announcement of the landmark Institute of Medicine (IOM) report which was based on Harvard Medical Practice Study I and II ${ }^{[2,3]}$ by the National Academy of Science ${ }^{[4]}$ in November 1999, numerous actions targeting patient safety were promoted through President Clinton's initiative to reduce preventable medical errors by 50 percent within five years of February 2000.

\footnotetext{
${ }^{*}$ Correspondence: Masahiro Hirose; Email: mhirose@med.shimane-u.ac.jp; Address: Department of Community-based Health Policy and Quality Management, Faculty of Medicine, Shimane University, Izumo, Shimane, 693-8501, Japan. 
President Clinton called for a nationwide system for reporting medical errors and asked the Congress for 20 million USD to create a Center for Quality Improvement and Patient Safety as part of the federal Agency for Healthcare Research and Quality (AHRQ) in the Department of Health and Human Services. ${ }^{[5,6]}$

The following adverse medical events occurred in Japan around 1999:

(1) Two men received the wrong operations at Yokohama City University Hospital (YCUH) directly due to a patient mix-up on January 11, 1999. ${ }^{[7,8]}$ At that time, only one nurse transported both patients to the operating room. In this case, the most problematic issue was the shortage of nursing staff.

(2) On February 11, 1999, a 58-year-old female died after surgery because she received disinfectant intravenously at Tokyo Metropolitan Hiroo Hospital. ${ }^{[9,10]}$ Instead, the main problems involved a lack of transparency and compliance with Article 21 of the Medical Practitioners Act. ${ }^{[11]}$

(3) In March 2000, an artificially ventilated 17-year-old girl died from acute alcohol poisoning at Kyoto University Hospital (KUH). A young nurse mistakenly placed alcohol into the humidifier of the ventilator in place of water. As in the YCUH case, in this case, the background factor was the shortage of nursing staff. ${ }^{[12,13]}$

(4) A 12-year-old girl died because of the failure of cardiopulmonary devices at Tokyo Women's Medical University Hospital (TWMUH) in March 2001, and the operating surgeon covered up errors and falsified medical records due to a lack of a sense of morality. This university hospital was stripped of its status as an "approved hospital with advanced technology" (Tokutei Kinou Byouin in Japanese) by the Ministry of Health, Labour, and Welfare (MHLW) in July 2002. ${ }^{[14]}$

In spring of 2001, the National University Hospital Council (NUHC) of Japan presented proposals for health care safety in collaboration with the Ministry of Education, Culture, Sports, Science and Technology (MEXT).

Subsequently, the MHLW established the Review Committee on Health Care Safety Measures to indicate the direction of health care safety in April 2002. It mandated all hospitals and clinics with beds to prepare four health care safety systems in 2002 and approved hospitals with advanced technology and qualified clinical training hospitals to take two additional actions in 2003.

Starting in 2004, administrators of target hospitals must submit medical accident reports to the Medical Accident Prevention Center of Japan Council for Quality Health Care (JCQHC) (Although a mandatory medical accident reporting system that might be relevant to the Patient Safety Reporting System (PSRS) system was initiated in 2004 in Japan, only 965 [mandatory: 274, voluntary: 691] out of the 8,540 domestic hospitals operating in 2013 participated). Furthermore, the Prevention Center of the JCQHC began to collect nationwide near-miss incident reports in 2005. As described, the basic systems for health care safety were developed systematically through bureaucratic initiatives. The period between 2000 and 2009 marks the creation of basic patient safety systems.

In May 2015, the two so-called approved hospitals with advanced technology, Gunma University Hospital and TWMUH were revoked because of deaths caused by patient safety problems. ${ }^{[15]}$

(5) Eight patients died at Gunma University Hospital after undergoing laparoscopic surgeries performed by a particular surgeon to treat liver diseases. ${ }^{[16]}$

(6) At TWMUH, a 2-year-old boy died after being injected with a powerful sedative, Propofol, contraindicated for administration to mechanically ventilated children. This hospital is facing the revocation of its status for the second time since 2002. ${ }^{[17,18]}$

Since 2010, several adverse medical events have occurred. This time period can be considered the beginning of a mindset focused on quality-driven patient safety.

The surgical case occurred directly due to a surgeon's inadequate skill, but the common cause in both cases was a lack of medical ethics and, indirectly, a lack of peer review beyond clinical departments (such as the "Morbidity and Mortality Conference (MMC)" in the US). Morioka emphasized governments' and physician groups' initiatives to improve awareness of medical ethics. ${ }^{[19]}$

Therefore, in addition to considering the shortage of health care professionals, the author of this study describes the health care system in Japan, particularly the patient safety system, by comparing it with the US system in an attempt to explore the factors that cause repeatedly stupid medical accidents in Japan.

\section{MeTHODS}

Surveys to find the current condition of patient safety system between Japan and the US had been performed in both countries and five studies had been conducted in order to explore the cause of medical accidents in Japan. 


\subsection{Surveys to find the status quo of patient safety- related systems in Japan and the US}

In order to collect the information about patient safety system in both coutries, the author directly visited patient safetyrelated organizatons in the US during the stay at Boston between October, 2006 and August, 2007, and collected patint safety-related references and books. Addtionally, the author collected the patient safety-related information after coming back to Japan, too.

\subsection{Five patient safety-related scientific studies}

To find the key to resolve the problems of Japanese patient safety, the author performed five scientific studies, including a statistical examination. All reported $p$-values were two-tailed, and the level of significance was set at $p<.05$.

\subsubsection{Study 1: A comparative study of health care profes- sionals' attitude toward patient safety between Japan and the $\mathrm{US}^{[20,21]}$}

When a witness with greater awareness of patient safety encounters an adverse medical event, he/she more quickly submits an incident report. The author created Lag time between the reporting date and the incident occurrence date as a novel quality indicator to examine health care professionals' awareness. The aim of two studies was to explore the difference in Lag time between health care professionals at KUH in Japan (the first study) and between professionals in Japan and the US (the second study).

\subsubsection{Study 2: A hospital survey on patient safety culture in Japan ${ }^{[22,23]}$}

A nationwide survey of patient safety culture in 37 hospitals $(18,469$ persons) was conducted using the Japanese version of the Hospital Survey on Patient Safety Culture questionnaire, ${ }^{[24]}$ originally developed by the AHRQ.${ }^{[25]}$ The questionnaire consists of 44 items to assess organizational and individual patient safety culture and to calculate the percent positive response (PPR) of twelve factors. Responses to all items were scored on a 5 -point scale $(1=$ strongly disagree $5=$ strongly agree).

\subsubsection{Study 3: A study on Japanese health care profession- als' sense of ethics ${ }^{[26]}$}

This study aimed to explore Japanese physicians' sense of medical ethics. Data on scores from 454 accredited hospitals, according to version 5.0 JCQHC accreditation standards, were obtained from the JCQHC website. The surveyors' scores were measured on a five-point scale for the items related to "Patients' rights and system for securing patient safety", including medical ethics.

Published by Sciedu Press
2.2.4 Study 4: A study on the situation of JCQHC accreditation in Japan ${ }^{[27]}$

The JCQHC began hospital accreditation in 1997. The characteristics of facilities accredited as general type hospitals according to the 2.0/3.0 version of the hospital accreditation standards were examined in this study. As of December 1, 2001, a total of 577 of 9,286 domestic hospitals had been accredited by the JCQHC. Many private-sector hospitals were small-sized hospitals.

\subsubsection{Study 5: A study on in-hospital patient safety sys- tems in Japan ${ }^{[22,28]}$}

A nationwide survey was conducted on the patient safety activities in hospitals implementing the Preferential Health Care Safety Countermeasure Fee (PHCSCF) as of April 1, 2012. Of the 2,674 hospitals targeted (all domestic hospitals: 8,706 as of June 1, 2012) in Japan, 669 hospitals responded.

In this study, the 669 participant hospitals were divided into three classes by the number of beds and PHCSCF classification: PHCSCF I ( 85 points) and II (35 points); PHCSCF I implementing hospitals with more than 401 beds (A: 173 hospitals); PHCSCF I implementing hospitals with less than 400 beds (B: 306 hospitals); and PHCSCF II implementing hospitals (C: 180 hospitals).

\section{RESULTS}

3.1 Surveys to find the status quo of patient safetyrelated systems in Japan and the US at the national/federal/public level

After the 1999 YCUH case, the NUHC of Japan proposed some countermeasures for health care safety in collaboration with the MEXT. ${ }^{[29]}$ One of these countermeasures was to assign a registered nurse as a risk manager at 42 national university hospitals (UHs) in 2003 and 2004. The National University Hospital Conference for Health Care Safety Management was established under the supervision of the NUHC of Japan. Since 2001, regular meetings have been held semiannually to discuss health care safety.

The In-Health Ministry Review Committee on Health Care Safety Measures discussed the current status of health care safety and determined the direction of health care safety in Japan, as follows: ${ }^{[30]}$

(1) Full enforcement of the establishment of health care safety systems in hospitals;

(2) Provision of useful information regarding measures for health care safety in hospitals;

(3) Ensuring health care safety related to drugs and medical devices;

(4) Well-developed health care safety education and training for hospital staff; 
(5) Establishment of a system for responding to patients' claims and consultation;

(6) Efforts to improve patient safety by the parties involved;

(7) Promotion of studies that provide evidence to improve health care safety.

The MHLW mandated all hospitals and clinics with beds to prepare four measures for health care safety as of October 1, 2002: to prepare guidelines for health care safety, to establish a committee on health care safety, to establish an incidentreporting system within hospitals, and to hold a health care safety seminar for hospital staff (in response to plan 1). ${ }^{[1]}$

Moreover, the MHLW mandated clinical training hospitals and approved hospitals with advanced technology to create a patient consultation service within the hospital as of April 1, 2003 (in response to plan 5). ${ }^{[32]}$

This allowed hospitals to calculate the PHCSCF (50 points) when meeting the requirement under the social insurance medical fee schedule based on the minor revision of Medical Service Act (MSA) on April 1, 2006. ${ }^{[33]}$ Four years later, on April 1, 2010, PHCSCF was divided into two classes, PHCSCF I (85 points) and PHCSCF II (35 points). ${ }^{[34]}$

Additionally, since 2004, the JCQHC Medical Accidents Prevention Center, which was renamed the Division of Medical Accident Prevention in 2012, has undertaken the nationwide Project to Collect Medical Near-Miss/Adverse Event Information. ${ }^{[35-37]}$

The JCQHC is a third-party hospital accreditation organization, ${ }^{[27]}$ and it has conducted various activities, such as the above project and the evaluation of medical services provided at hospitals, to maintain public confidence in health care services and improve the quality of the services (in response to plan 2).

Following the Reorganization and Rationalization Plan for Special Public Corporations that was approved in a Cabinet meeting in 2001 and the plans for health care safety proposed by the In-Health Ministry Committee (in response to plan 3), the Pharmaceuticals and Medical Devices Agency was established and came into service on April 1, 2004, according to the law.

With regard to plan 4, when the PHCSCF is implemented, one of the requirements is to assign a qualified health care professional to attend a minimum of forty hours of a seminar for health care safety managers. Although the content of the seminar was not clearly defined at that time, the Review Committee indicated the guidelines for the seminar in 2007. ${ }^{[38]}$
In response to plan 6, the MHLW initiated Health Care Safety Promotion Week in 2008 as one of the "Health Care Safety Nationwide Collaborative Actions" to address the plans to health care safety among health care-related organizations and to improve Japanese people's understanding of health care safety.

In response to plan 7, the MHLW encourages research institutions, including UHs, to conduct studies on health care safety to obtain evidence on how to improve health care safety.

Furthermore, in a social environment of rising concern about health care safety, the MHLW revised the MSA for the fifth time with the title "Securing Patient Safety". The Law is defined in paragraphs 9 to 12 of article 6 in the Act. The phrase "health care safety", rather than "patient safety", was used in the Act for the first time in Japanese history. ${ }^{[39]}$

In the US, various institutions and government agencies for patient safety emerged after the publication of the IOM report. The president at that time received a new report on medical errors from the administration's Quality Interagency Coordination Task Force (QuIC) ${ }^{[40]}$ and announced a series of landmark initiatives to promote patient safety.

Consistent with the QuIC recommendations, the president called for the following:

(1) A new Center for Patient Safety;

(2) A requirement that each of the more than 6,000 hospitals participating in Medicare have error reduction programs in place;

(3) New actions to improve the safety of medications, blood products, and medical devices;

(4) A mandatory reporting system in the 500 military hospitals and clinics that serve more than 8 million patients;

(5) A phased-in nationwide state-based system of mandatory and voluntary error reporting.

With respect to items 1 and 2, changes were initiated in the Department of Veterans Affairs (VA) in 1995. After the Expert Advisory Panel in 1997, the VA National Center for Patient Safety (NCPS) was established in 1999. ${ }^{[41]}$ James P. Bagian ${ }^{[42]}$ who was a National Astronautics and Space Administration (NASA) astronaut, became the Director of NCPS to lead the VA's patient safety efforts and provide patient safety programs. ${ }^{[43,44]}$

The Patient Safety Improvement Corps (PSIC) was developed in 2003 through a joint effort by the AHRQ and the NCPS and operated in partnership with these organizations. The PSIC was a nationwide training program conducted as part of AHRQ's overall patient safety initiative and held three times in 2005 and 2006. ${ }^{[45]}$ 
In terms of items 4 and 5, the NCPS Patient Safety Information System (PSIS) is a de-identified internal, confidential, and non-punitive reporting system, and VA hospitals' incidents are sent to NCPS through PSIS. The system allows NCPS to electronically document and analyze patient safety information from across the VA. ${ }^{[45]}$

The PSRS is a program that NASA developed in 2000 in collaboration with NCPS to examine issues related to patient safety. ${ }^{[46]}$ Staff in all medical systems can voluntarily file a report using PSRS's original format. PSRS plays a complementary role in patient safety in the US.

Although the Agency for Health Care Policy and Research was originally established in 1989, it was reauthorized as the AHRQ under the Healthcare Research and Quality Act of 1999. Its mission is to produce evidence to make health care safer, higher quality, more accessible, more equitable, and more affordable.

\section{At the hospital level in Japan and the US}

Patient Safety Division at KUH and Patient Safety Team at $B W H$ and Incident Reporting System.

Following an adverse medical accident in 2000, KUH, a teaching affiliate of Kyoto University School of Medicine in Kyoto, Japan, established a Patient Safety Division in April 2002. Furthermore, it assigned a qualified surgeon and a registered nurse as full-time risk managers. ${ }^{[20,47]}$

In May 2001, BWH, a teaching affiliate of Harvard Medical School in Boston, created a Patient Safety Team that consists of a medical director ( $30 \%$ time), a full-time patient safety manager, a full-time pharmacist and a full-time data manager. ${ }^{[21,48]}$

Witnesses of events can submit an incident report to Patient safety Division at KUH via fax and to Patient Safety Team at BWH via a web-based hospital-wide system that was adopted in 2003. An electrical incident-reporting system was implemented at KUH in August 2005. ${ }^{[20,21,47]}$

\section{$M M C$ at $B W H$}

The MMC has long been part of the practice of medicine. Earnest Amory Codman, an early $20^{t h}$-century surgeon, championed the evaluation of clinical practice by introducing the end result system at Massachusetts General Hospital. The MMC was developed based on his idea. ${ }^{[49-51]}$

The MMC begins at 7:00 a.m. at Carrie Hall every Wednesday morning at BWH. Nearly a hundred people, from the interns to the chairman of surgery and all surgeons, attend the MMC and discuss patients' status and complications after surgery. In the US, residents must attend this MMC during their surgical residency program.

Published by Sciedu Press
By contrast, most hospitals in Japan do not regularly hold an MMC because Japanese physicians do not understand its essence.

Medical license and medical licensure renewal system in Japan and the US

In Japan, the Ministry of Health and Welfare (until 2001 and subsequently the MHLW after the merger with the Ministry of Labour, 1948) implemented the so-called Internship System for Clinical Training in 1946 under the supervision of the Allied Occupation forces. The Medical Practitioner's Law was established in $1948^{[52]}$ and states that all individuals who wish to become physicians in Japan must pass the national medical examination and receive a national medical license.

However, partially because medical graduates were not secured in their health care professional position for life, the internship system was abolished and a clinical training residency program was established in 1968. Since 2004, the MHLW has conducted a two-year mandatory primary residency program and a matching examination for residency between hospitals and new medical graduates. Prior to this mandatory system, MEXT introduced a ComputerBased Test and Objective Structured Clinical Examination in 2002. ${ }^{[53]}$

There is one other way to become a physician in Japan. The MHLW accepts individuals who graduated from foreign medical schools abroad and who pass a national medical examination review of eligibility requirements. However, the national medical examination is conducted in Japanese. Hence, it is difficult for foreigners to become physicians in Japan.

Despite debate over the propriety of the medical license renewal system, the Japanese health care system continues to lack its own renewal system. Furthermore, the Japan Medical Association (JMA) established a continuing medical education (CME) system and provides the CME for JMA voluntary members. ${ }^{[54,55]}$ Because the JMA-CME is limited, a CME by a third party should be established immediately. ${ }^{[19]}$

In the US, physician certification and licensure requirements for those who obtained their medical education abroad have changed over time. After World War II, increasing numbers of physicians who had trained outside the US sought opportunities in the US health care system, and the need to assess the training and qualifications of these physicians became evident. ${ }^{[56]}$

In 1956, the Educational Commission for Foreign Medical Graduates (ECFMG) was established to ensure that graduates outside the US and Canada were qualified to enter graduate residency programs and to pursue licensure in the US. ${ }^{[56,57]}$ 
Beginning in 1988, international medical graduates were allowed to take the same professional examinations as US medical school students and graduates. Between 1988 and 1993, international medical graduates could take either the Foreign Medical Graduates Examination in the Medical Sciences (FMGEMS) or the National Board of Medical Examiners' Part I and Part II examinations.

Beginning in 1994, the FMGEMS was replaced with the US Medical Licensing Examination TM Step 1 and Step 2 examinations. In 1998, the ECFMG incorporated an additional performance-based examination, the clinical skills assessment, into the certification process. ${ }^{[58-60]}$ Additionally, to work at a hospital in the US, a licensed physician must apply to the state health department of the hospital.

An American physician must renew his/her medical license every several years to meet the requirement of CME credits.

\subsection{Scientific studies: The key to resolving the problems of Japanese patient safety}

3.2.1 Study 1: A comparative study of health care professionals' attitude toward patient safety between Japan and the $U S^{[20,21]}$

In the first study at KUH, the 6,880 incident reports filed by physicians and nurses were examined. Physicians reported far fewer incidents overall (462 vs. 6,418), and in univariate analyses, the Lag time was significantly longer for physicians than for nurses ( 3.79 vs. 2.20 days; $p=.001$ ).

In the second report, 3,084 incident reports filed at KUH and 4,102 reports filed at BWH were examined. Unadjusted Lag times were significantly longer for physicians at KUH than for those at BWH ( $4.3 \pm 5.2$ vs. $2.8 \pm 8.7$ days, $p<.0001)$ and were longer at KUH than at BWH $(3.1 \pm 4.1$ vs. $1.0 \pm 4.1$ days, $p<.0001)$.

This result indicated that the physicians working at KUH were less willing to submit incident reports than those at $\mathrm{BWH}$; thus, the physicians at KUH may have a lower sense of ethics than those at BWH.

\subsubsection{Study 2: A hospital survey on patient safety culture in Japan ${ }^{[22,23]}$}

The Percent Positive Response of twelve factors, with the exception of Factor 3 (Frequency of events reported), for health care professionals in Japan was lower than the responses in Sorra's report for the US.

Furthermore, the Percent Positive Response of Factor 9 (Staffing) in Japan (29.3\%) was lower than that in the US $(55.0 \%)$. These finding suggests that a culture of patient safety may be fostered less at hospitals in Japan than in the US and that health care professionals in Japan feel busier than those in the US.

\subsubsection{Study 3: A study on Japanese health care profession- als' sense of ethics ${ }^{[26]}$}

Table 1 presents the result of this study. Out of 454 hospitals, $41 \mathrm{UHs}$ and 411 general clinical training hospitals (GHs) were targeted. The mean scores ( \pm SE: standard error) of GHs for items on ethics 2.1.2 "Policy on professional ethics is clearly indicated" and 2.1.3 "Policy on clinical ethics is clearly indicated" were $3.46 \pm 0.026$ and $3.22 \pm 0.024$, respectively. Similarly, the mean scores of GHs for items on research 2.1.4 "Policy on clinical trial studies is clearly indicated" and 2.1.5 "Policy on clinical researches is clearly indicated" were $3.87 \pm 0.019$ and $3.75 \pm 0.024$, respectively. The scores of GHs and UHs for items on ethics were statistically lower than those on research (Wilcoxon test: $p<.001$ ). These findings concluded that Japanese physicians might lack a sense of ethics.

\subsubsection{Study 4: A study on the situation of JCQHC accred- itation in Japan $^{[27]}$}

The ratios of accredited hospitals to domestic hospitals by the number of beds at that time were 0.007 for hospitals with 20 to 49 beds (number of accredited hospitals/domestic hospitals $=10 / 143), 0.026(63 / 2,435)$ for hospitals with 50 to 99 beds, $0.050(74 / 1,464)$ for hospitals with 100 to 149 beds, $0.062(71 / 1,140)$ for hospitals with 150 to 199 beds, $0.079(98 / 1,244)$ for hospitals with 200 to 299 beds, 0.118 (87/745) for hospitals with 300 to 399 beds, $0.173(63 / 358)$ for hospitals with 400 to 499 beds, and 0.223 (101/497) for hospitals with more than 500 beds. Thus, the ratios gradually and linearly increased among larger-sized hospitals.

As Figure 1 indicates, the hospital accreditation rate increased until 2004 and peaked in 2009. Since then, the rate has been slowly but steadily decreasing. Although the importance of hospital accreditation has been debated, the rate was $26.6 \%(2,267 / 8,512)$ as of May 14, 2015. This finding indicated that Japanese physicians are reluctant to obtain hospital accreditation.

\subsubsection{Study 5: A study on in-hospital patient safety sys- tems in Japan $^{[22,28]}$}

Many hospitals in A and B were large and owned by the national, municipal and public sectors, but most hospitals in $\mathrm{C}$ were small-sized or medical corporations.

According to this study, the mean ( $\pm S D$ : standard deviation) numbers of nurses assigned as full-time risk managers were $1.25 \pm 0.70$ in $\mathrm{A}, 1.06 \pm 0.94$ in $\mathrm{B}$ and $0.23 \pm 0.93$ in $\mathrm{C}$. The mean $( \pm S D)$ numbers of incident reports filed by all staff were $2,023 \pm 1,550$ in $\mathrm{A}, 779 \pm 649$ in B and $428 \pm 455$ in C. In terms of hospital accreditation by JC- 
QHC, the accreditation rate (accredited hospitals/participant hospitals in each group) was $90.1 \%$ (156/173) in A, 68.8\% $(203 / 295)$ in B, and $43.7 \%(76 / 174)$ in $\mathrm{C}$.

This result demonstrated that small-sized hospitals suffer from a serious shortage of staff and do not assign health care professionals as risk managers. Furthermore, smaller-sized hospitals experience difficulty in achieving high performance for patient safety activity in Japan and may be less interested in the quality of health care, such as hospital accreditation.

Table 1. Patient safety culture in Japan and the US

\begin{tabular}{|c|c|c|c|c|}
\hline \multirow{2}{*}{ Patient Safety Composites } & \multicolumn{2}{|c|}{ Japan (37: 16,670) } & \multicolumn{2}{|c|}{ USA (1,032: 472,397) } \\
\hline & mean PPR & $S D$ & mean PPR & $S D$ \\
\hline Factor 1: Communication Openess & 44.1 & 11.69 & 62.0 & 6.54 \\
\hline Factor 2: Feedback \& Communication About Error & 60.9 & 9.80 & 64.0 & 8.20 \\
\hline Factor 3: Frequency of Events Reported & 64.2 & 5.67 & 63.0 & 7.52 \\
\hline Factor 4: Handsoffs \& Transitions & 39.4 & 11.70 & 45.0 & 11.08 \\
\hline Factor 5: Management Support for Patient Safety & 46.1 & 10.53 & 72.0 & 7.08 \\
\hline Factor 6: Nopunitive Response to Errors & 43.0 & 13.40 & 44.0 & 8.47 \\
\hline Factor 7: Organizational Learning-Continuous Improvement & 55.0 & 12.70 & 72.0 & 9.30 \\
\hline Factor 8: Overall Perceptions of Patient Safety & 45.5 & 3.86 & 66.0 & 8.26 \\
\hline Factor 9: Staffing & 29.3 & 24.02 & 57.0 & 9.36 \\
\hline Factor 10: Supervisor/Manager Expectations \& Actions & 69.4 & 6.88 & 75.0 & 6.37 \\
\hline \multicolumn{5}{|l|}{ Promoting Patient Safety } \\
\hline Factor 11: Teamwork Across Units & 42.1 & 14.09 & 58.0 & 10.04 \\
\hline Factor 12: Teamwork Within Units & 74.3 & 4.42 & 80.0 & 5.84 \\
\hline
\end{tabular}

Note. PPR: Percent Positive response; SD: standard deviation; The numbers in parenthesis indicated number of participant hospitals and hospital staff.

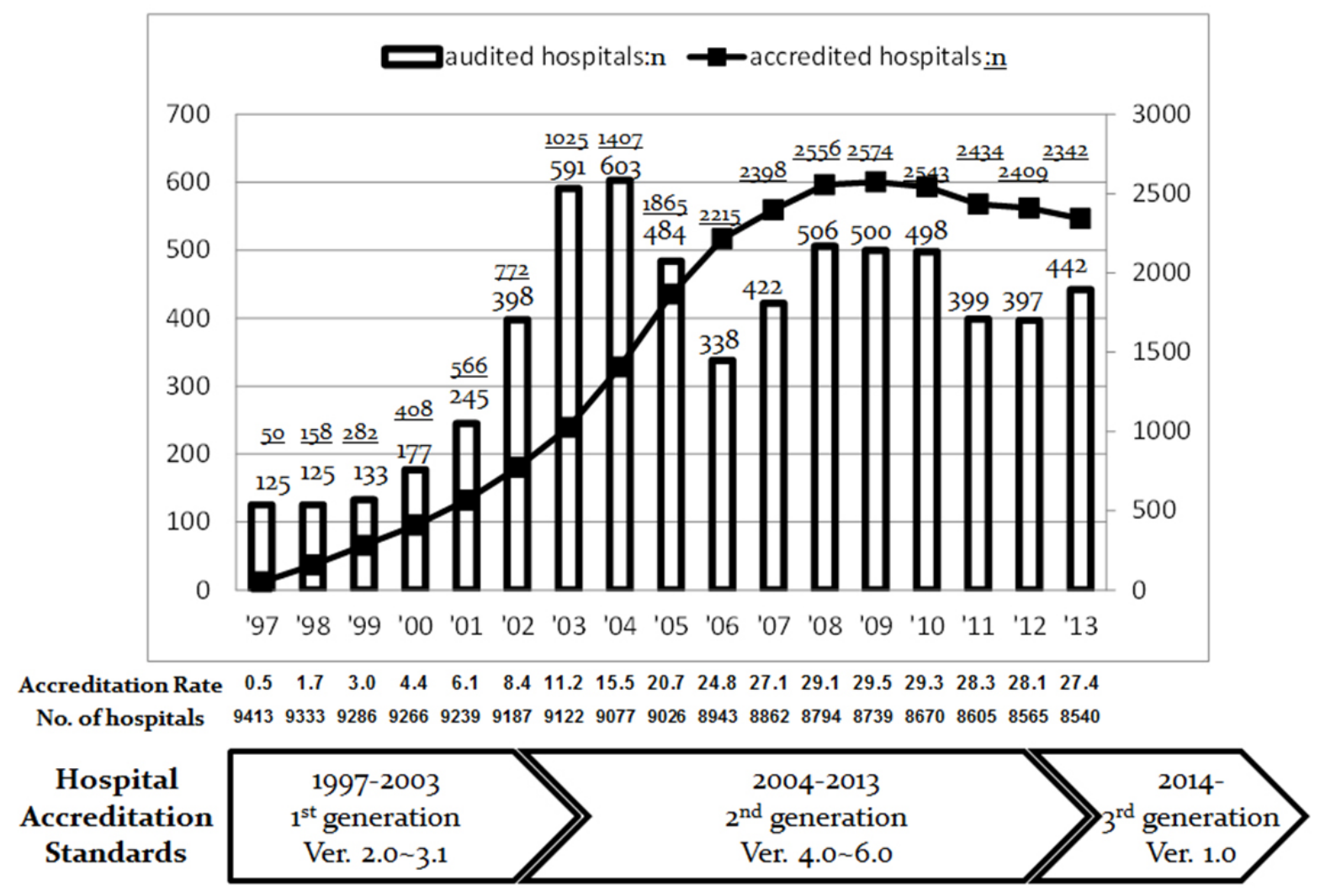

Figure 1. Annual trends of number of audited and accredited hospitals in Japan 


\section{Discussion}

The history of patient safety in Japan can be roughly divided into two terms: the first term involving the creation of the patient safety infrastructure and the second term involving the duration of quality-driven patient safety.

In the first term, after the 1999 YUCH case, hospitals and clinics with beds have prepared patient safety systems according to the law, health care professionals have made efforts to secure patient safety, and drug and medical device companies have developed and improved their products for patient safety. Adverse medical events in this term occurred in the context of a shortage of health care professionals, especially nursing staff. ${ }^{[27]}$

According to the 2013 OECD data, although the number of practicing doctors per 1,000 population in 2009 was 2.2 for Japan and 2.4 for the US, the number of hospital beds per 1,000 population was 13.7 for Japan and 3.1 for the US ${ }^{[61]}$ (Organisation for Economic Co-operation and Development 2011). In 2009, Japan had 8,739 hospitals ${ }^{[62]}$ and the US had $5,795 .{ }^{[63]}$ It suggests that health professionals are spread too thin. As a result, they always feel very busy in Japan.

The excessive number of hospitals in Japan is partially because of the large number of small-sized and private-sector hospitals with less than 150 beds $\left(4,728\right.$ in 2009). ${ }^{[62]}$

For example, based on the results of study 2 on Hospital Survey of Patient Safety Culture, the average Percent Positive Response of Factor 9 (Staffing) was $29.3 \%$ in Japan and $55.0 \%$ in the US. This represents a substantial difference between Japan and the US. The number of hospitals in Japan has to be properly adjusted in order to put physicians and nurses there for securing patient safety.

Another relevant factor is health care workers' awareness, especially physicians' awareness. Study 1 examined physicians' awareness of patient safety and sense of medical ethics and presented evidence using Lag time between the occurrence and submission of an incident. ${ }^{[20,21]}$ Study 2 used the Hospital Survey of Patient Safety Culture questionnaire to examine the individual and organizational perspectives, ${ }^{[22,28]}$ and study 5 provided evidence using surveyors' scores of items regarding patient safety and medical ethics extracted from the JCQHC website. ${ }^{[26]}$ Based on the results of these studies, Japanese physician's lack of a sense of medical ethics contribute to a factor of stupid medical accidents.

Finally, the third issue is the framework needed to secure patient safety. Table 2 presents a summary of patient safetyrelated systems and events. This table shows that the countermeasures for patient safety in Japan were presented incrementally rather than systematically and, thus, burdened front-line health care professionals.

Considering the policies and specific actions, there seems to be a large difference in the paths to patient safety between Japan and the US. After the landmark YCUH adverse event case, following the National University Hospital Council of Japan's proposal, the Education Ministry determined to assign a registered nurse as a full-time risk manager at only 42 national university hospitals of the approximately 9,000 domestic hospitals in Japan.

Although the Health Ministry implemented the preferential health care safety countermeasure fee system in 2006, one of the requirements is to assign a qualified health care professional (as a health care safety manager) to attend a patient safety seminar lasting more than 40 hours. However, as the guidelines of the seminar program were only recently indicated in 2007, the Japanese central government seems unwilling to provide financial and human resources for this important policy issue.

By contrast, the US government has been responsible for taking numerous actions according to the president's statement. The VA NCPS was established, and a director was assigned. The NCPS attempted to train health care professionals from all US states in collaboration with AHRQ, and PSRS was created in collaboration with NCPS and NASA under the supervision of the government.

Unlike health care professionals in the US, Japanese health care professionals do not have the opportunity to attend optimal patient safety seminars at the national level. NCPS holds a patient safety seminar for all state health care professionals, including administrative posts, for the purpose of standardizing patient safety at the federal level. Plans are in place to create a patient safety incident reporting system equivalent to the system in the US.

Thus, Japan can incrementally implement a policy for health care safety based on bureaucratism, as frequently noted in other fields, including economics and foreign diplomacy at home and abroad. By contrast, the US has a planned policy for patient safety based on presidentialism. In the United Kingdom, a higher level of political accountability has led British politicians to play a greater role in promoting patientled reforms compared with their Japanese counterparts. ${ }^{[64]}$

Table 3 presents the systems that govern physicians to secure patient safety and control the quality of health care. When comparing Japanese systems with those in the US, Japanese systems are quite generous to Japanese physicians. As shown by the statistics on disciplining physicians, once a physician obtains a medical license in Japan, he/she remains a physician throughout his/her life unless a crime is committed. The 
Japan Medical Association does not promote Japanese physi- sense of ethics. cians' efforts to be involved in patient safety or to have a

Table 2. Summary of patient safety-related events and systems between Japan and the US

\begin{tabular}{|c|c|}
\hline Japan & $\begin{array}{c}\text { US } \\
\end{array}$ \\
\hline • 1995 JCQHC est. & - 1910 End result system by Dr. Earnest Codman at Massachusetts \\
\hline - 1997 JCQHC hospital accreditation initiated. & General Hospital \\
\hline Duration of the creation of basic health care safety infrastructure & - 1913 American College of Surgeons est. \\
\hline - 1999 The landmark Yokohama City University Hospital case; Tokyo & - $19161^{\text {st }}$ Hospital Investigation: American College of Surgeons \\
\hline Metropolitan Hiroo Hospital case & - 1951 Joint Commission on Accreditation of Hospitals est. \\
\hline - 2000 Kyoto University Hospital case; TWMUH case & - 1995 Dana-Faber Cancer Institute case: Big Dose Chemotherapy case \\
\hline - 2001 National University Hospitals Council of Japan’s proposal & - 1999 VA NCPS est. \\
\hline - 2002.04 Patient Safety Division at Kyoto University Hospital est. & $\sqrt{ }$ Announcement of the Institute of Medicine report \\
\hline - 2002.07 MHLW Review Committee on Health Care Measures est. & $\S$ Harvard Medical Practice Study I: New York \\
\hline - 2002.10 MHLW mandatory HCS systems for hospitals \& clinics with & $\S$ Harvard Medical Practice Study II: Utah \& Colorado \\
\hline beds & $\sqrt{ } 2000$ President's announcement to reduce medical errors \\
\hline - 2003.04 MHLW additional mandatory HCS systems for HTA \& CTH & $\S 1999$ AHRQ \\
\hline • 2004.04 Pharmaceutical and Medical Devices Agency est. & $\S 2000$ Patient Safety Information System \\
\hline • 2004.10 JCQHC Medical Accident Prevention Center est.; Mandatory & $\S 2000$ Patient Safety Reporting System (with NASA) \\
\hline Medical Accident Reporting initiated. & § 2006-07 Patient Safety Improvement Corps (NCPS \& AHRQ) \\
\hline - $2006.045^{\text {th }}$ Revision of Medical Service Act: Health Care Safety & • 2001 Patient Safety Team at Brigham \& Women’s Hospital est. \\
\hline • 2006.04 Preferential HCS Countermeasure Fee initiated. & - 2005 Patient Safety and Quality Improvement Act 2005 \\
\hline \multicolumn{2}{|l|}{$\begin{array}{l}\text { Duration of the change the mindset to patient-oriented patient } \\
\text { safety }\end{array}$} \\
\hline \multicolumn{2}{|l|}{ - 2010.04 Preferential HCS Countermeasure Fee revised. } \\
\hline \multicolumn{2}{|l|}{ • 2015.07 Two university hospitals' qualifications revoked by MHLW } \\
\hline \multicolumn{2}{|l|}{$\sqrt{ }$ Gunma University Hospital case } \\
\hline$\sqrt{ }$ TWMUH case with Propofol & \\
\hline • 2015.10 Medical Accident Investigation System initiated. & \\
\hline
\end{tabular}

Note. JCQHC: Japan Council for Health Care Quality; TWMUH: Tokyo Women's Medical University Hospital; MHLW: Ministry of Health, Labour, and Welfare; HCS: Health care safety; HTA: hospitals with advanced technology; CTH: clinical training hospitals; NASA: National Aeronautics and Space Administration; NCPS: National Center for Patient Safety; AHRQ: Agency for Healthcare Research and Quality.

A surgeon working at Massachusetts General Hospital implemented the end result system based on patients' perspective at the beginning of the $20^{\text {th }}$ century, and this system was expanded to the MMC as a peer review system beyond clinical departments and the Joint Commission as a peer-reviewed hospital accreditation organization. By contrast, Japanese physicians do not fully understand the MMC and the hospital accreditation system.

Why is patient safety in Japan and the US different? It appears as though health care professionals and policy makers in Japan may believe that the Japanese health care system is thoroughly sufficient because the WHO report gave Japan the top rank in global health system attainment in 2000. ${ }^{[65]}$ Finally, they may subconsciously pay little attention to patient safety and patient-centered health care due to their lack of a sense of medical ethics.
Figure 2 presents the development of Japanese medicine. Looking back at the history of the development of Japan, at the time of the Meiji Restoration, the Japanese people did not change spontaneously. Rather, they changed extrinsically because in those days, the government was obliged to change in response to external pressure from the international community. The Meiji government implemented German medicine and established the University of Tokyo's Faculty of Medicine. Since the implementation of German medicine, physicians have had greater respect for research medicine than for clinical medicine.

When Japan was defeated in the Pacific War, physicians had the opportunity to extrinsically change their perspective from research medicine to clinical medicine. Japanese physicians, including medical professors, witnessed American medicine in harmony with research medicine and clinical medicine. 
However, because most of them had experienced the oppor- to focus on studies to rebuild their departments without realtunity to study overseas in German, they made every effort izing that American medicine was better.

Table 3. Summary of patient safety-related organizations and systems between Japan and the US

\begin{tabular}{|c|c|c|c|c|}
\hline Organizations/Systems & \multicolumn{2}{|c|}{ Japan } & \multicolumn{2}{|l|}{ US } \\
\hline $\begin{array}{l}\text { National Medical Association and } \\
\text { Title of Code of Ethics }\end{array}$ & \multicolumn{2}{|c|}{$\begin{array}{l}\text { Japan Medical Association } \\
\text { (Voluntary/38.3\% in 2007) } \\
\text { Guideline of Medical Ethics for Physicians }\end{array}$} & \multicolumn{2}{|c|}{$\begin{array}{l}\text { American Medical Association } \\
\text { (Voluntary/ 60\% in 2007) } \\
\text { Code of Medical Ethics }\end{array}$} \\
\hline Organizations governing physicians & \multicolumn{2}{|c|}{ Ministry of Health, Labour, and Welfare } & \multicolumn{2}{|c|}{$\begin{array}{l}\text { State Medical Licensing Board } \\
\text { (third-party organization) }\end{array}$} \\
\hline $\begin{array}{l}\text { Statistics regarding } \\
\text { physicians disciplined (2001) } \\
\text { (cited from Morioka 2012) }\end{array}$ & $\begin{array}{l}\text { Physicians: } \\
\text { - Instances: } \\
\text { - Revocation of license: } \\
\text { - Suspension of license: } \\
\text { - Fine: }\end{array}$ & $\begin{array}{l}240,908 \\
48 \\
6 \\
42 \\
-\end{array}$ & $\begin{array}{l}\text { Physicians: } \\
\text { - Instances: } \\
\text { - Revocation of license: } \\
\text { - Suspension of license: } \\
\text { - Fine: }\end{array}$ & $\begin{array}{l}701,249 \\
3,401 \\
1,642 \\
745 \\
1,014\end{array}$ \\
\hline Medical licensure & \multicolumn{2}{|c|}{$\begin{array}{l}\text { - Virtually, foreigners omitted } \\
\text { - National medical examination }\end{array}$} & \multicolumn{2}{|c|}{$\begin{array}{l}\text { All graduates from medical school } \\
\text { - National medical exam } \\
\text { - License required to practice medicine }\end{array}$} \\
\hline Medical license renewal system & \multicolumn{2}{|l|}{ None } & \multicolumn{2}{|c|}{ Required } \\
\hline Lifelong medical education & \multicolumn{2}{|l|}{$\begin{array}{l}\text { Japan Medical Associatio } \\
\text { - Members only } \\
\text { - Voluntary }\end{array}$} & \multicolumn{2}{|c|}{$\begin{array}{l}\text { American Medical Association } \\
\text { - Members only } \\
\text { - Voluntary but required for license renewal }\end{array}$} \\
\hline $\begin{array}{l}\text { Morbidity \& Mortality Conference } \\
\text { beyond clinical departments }\end{array}$ & \multicolumn{2}{|l|}{ Almost none } & \multicolumn{2}{|c|}{ Mandatory for surgical residency } \\
\hline Hospital accreditation performance & \multicolumn{2}{|c|}{$\begin{array}{l}\text { Japan Council for Quality Health Care (1995) } \\
\text { - Accreditation: since } 1997 \text {, hospitals only } \\
\text { - Health insurance hospitals: not required } \\
\text { - Accreditation rate: } 26.3 \% \text { (2,228/8,485: 2015) }\end{array}$} & \multicolumn{2}{|c|}{$\begin{array}{l}\text { Joint Commission (1957, renamed 2007) } \\
\text { - Accreditation: since 1957, health care facilities } \\
\text { - Medicare and Medicaid Services: required } \\
\text { - Accreditation rate: approx. } 88 \% \text { (2016) }\end{array}$} \\
\hline
\end{tabular}

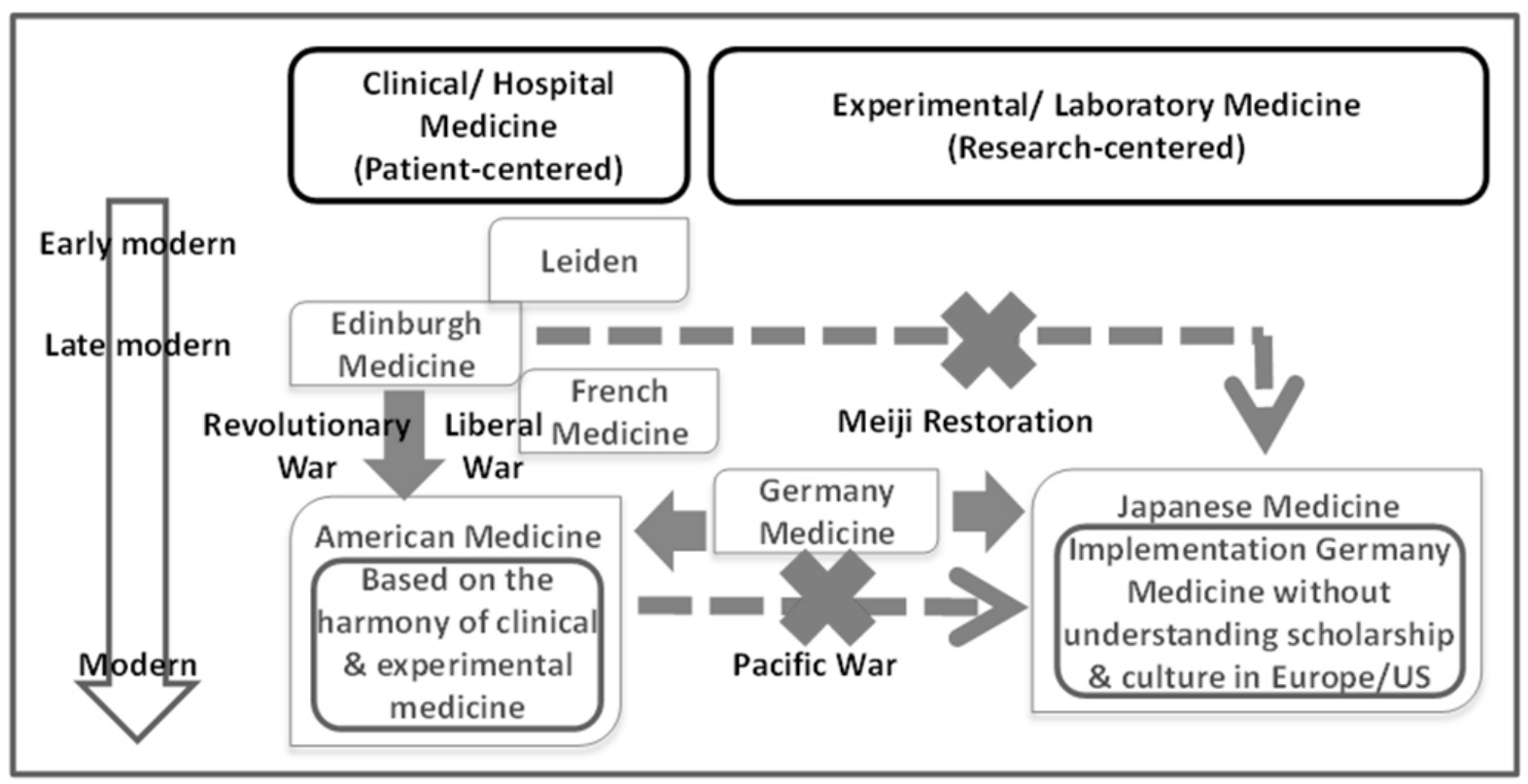

Figure 2. Development of Japanese medicine

By contrast, most American medical researchers had stud- tury. They absorbed Edinburgh medicine and established ied abroad in Edinburgh, Scotland, and they learned the origin of clinical medicine in the first half of the 19th cenAmerican medicine. However, in the second half of the 19th century, American researchers realized that many problems 
remained unsolved by clinical medicine and began to focus on research medicine. Hence, American medicine harmonized clinical and research medicine. ${ }^{[66]}$

\section{Conclusions}

This study compared the Japanese health care system, including the patient safety system, with the US system in order to explore the factors associated with medical accidents in Japan. On the background of relatively shortage of health care professionals due to too many hospitals, as Japanese research-oriented physicians lack a sense of ethics and professionalism and they failed to truly understand the MMC and JCQHC's hospital accreditation performance based on a peer-review system, adverse medical events repeatedly occurred in Japan. Additionally, the important structure to govern pyhisinas is not sufficient and generous to physicians.

Japanese policy makers should be responsible for restructuring the national organization for patient safety, and for creating the national system appropriately governs physcians. Japanese health care providers and the government must change their perspectives on medical ethics and patient safety by learning from the US.

\section{ACKNOWLEDGements}

The author wishes to acknowledge the Abe Fellowship Program for support for the study "Comparison of Factors Associated with Medical Accidents between Japan and the US" and for the author's stay in Boston, MA.

The author also wishes to acknowledge the academic members of the Kyoto University School of Public Health, Professor Yuichi Imanaka and the Harvard School of Public Health, Professor R. Heather Palmer, Professor David W. Bates, and Professor Atul A. Gawande, for their support during the research.

\section{Conflicts of InTerest Disclosure}

The authors declare they have no conflicts of interest.

\section{REFERENCES}

[1] The Hippocratic Oath. National Library of Medicine, National Institutes of Health. Translated by Michael North. Available from: https://www.nlm.nih.gov/hmd/greek/greek_oath.html

[2] Brennan TA, Leape LL, Laird NM, et al. Incidence of adverse events and negligence in hospitalized patients. Results of the Harvard Medical Practice Study I. N Engl J Med. 1991; 324(6): 370-6. http://dx.doi.org/10.1056/NEJM199102073240604

[3] Leape LL, Brennan TA, Laird N, et al. The nature of adverse events in hospitalized patients. Results of the Harvard medical Practice Study II. N Engl J Med. 1991; 324(6): 377-84. http: //dx.doi.org/10.1056/NEJM199102073240605

[4] Kohn LT, Corrigan JM, Donaldson MS. To Err Is Human-Building a Safer Health System. Washington, DC: National Academies Press; 1999.

[5] Pear, Robert, Clinton to order steps to reduce medical mistakes. The New York Times. 2000 Feb 22. Available from: http://www. nyti mes.com/2000/02/22/us/clinton-to-order-steps-to-r educe-medical-mistakes.html?pagewanted=all

[6] Charatan F. Clinton acts to reduce medical mistakes. Brit Med J. 2000 Mar 4; 320(7235): 597. http://dx.doi .org/10.1136/bmj . 320 .7235 .597

[7] Yokohama City University Hospital Medical Accident Investigation Board. Overview of the medical accident at Yokohama City University Hospital. 1999 Mar 24. (Japanese). Available from: http: //www.yokohama-cu.ac.jp/kaikaku/BK3/bk3.html

[8] Hashimoto M. Safety management activities of Yokohama City University Hospital- safety management is the platform of quality improvement. Nihon Geka Gakkai Zasshi. 2003; 104(1): 35-9. (Japanese with English Abstract). PMid: 12624976.

[9] atal IV drip spurs malpractice probe in Hiroo. The Japan Times. 1999 Mar 16. Available from: http://www.japantimes.co.jp /news/1999/03/16/national/fatal-iv-drip-spurs-mal practice-probe-in-hiroo/\#.V1kedbuLSUl
[10] Tokyo Metropolitan Hiroo Hospital Medical Accident Investigation Board. Report on investigation of medical accident at Tokyo Metropolitan Hiroo Hospital. 1999 Aug (Japanese). http://dx.d oi.org/10.1093/heapol/czh031

[11] Higuchi N. Should medical errors be judged by the criminal court? Japan Medical Association Journal. 2012; 55(2): 128-38.

[12] Kyoto District Court. Kyoto District Court Decision, Court Case number: 13 of Heisei (Wa) 2820; title of the case: damages. 2006 Nov 1 (Japanese). Available from: http://www . courts.go.jp/a pp/files/hanrei_jp/797/033797_hanrei.pdf

[13] Japanese Nursing Association. Osaka High Court Decision. 2004 Jul 13 (Japanese). Available from: https://www.nurse.or.jp/nurs ing/practice/anzen/pdf/kyoudai.pdf

[14] Malpractice and coverups. The Japan Times. 2002 Jul 13. Available from: http://st.japantimes.co.jp/english_news/e ditorial/2002/ed20020719.htm?print=noframe

[15] Hospitals in Tokyo, Gunma might be stripped of 'advanced treatment' status. The Japan Times. 2015 May 1. Available from: http: //www.japantimes.co.jp/news/2015/05/01/national/sc ience-health/tokyo-gunma-hospitals-may-lose-advan ced-medical-care-status-safety-issues/\#.VgMMx9

[16] Gunma University Hospital Adverse Medical Accident Investigation Board. Report on adverse medical event after laparoscopic surgery for treatment of liver disease at Gunma University Hospital. 2015 Feb 12. Available from: http://hospital .med.gunma-u.ac.jp /wp-content/uploads/2015/03/saisyuu_houkokusyo.pdf

[17] Tokyo hospital used propofol on 63 children. The Japan Times. 2014 Jun 6. Available from: http: //www.japantimes.co.jp/news/2014/06/06/nationa 1/tokyo-hospital-used-propofol-63-children/\#.VvYB8

[18] Tokyo Women's Medical University Hospital Medical Accident Investigation Board. Report on investigation of medical accident at Tokyo Women's Medical University Hospital-A death case after surgery for cervical cystic lymphangioma. 2015 Feb (Japanese). 
Available from: http://www.twmu.ac.jp/info-twmu/images /investigation-report.pdf

[19] Morioka Y. Initiatives by the government and physician groups to improve awareness of medical ethics: Plans in Japan. Proc Jpn Acad Ser B Phys Biol Sci. 2012; 88(4): 144-51. http://dx.doi.org/1 $0.2183 / \mathrm{pjab} .88 .144$

[20] Hirose M, Regenbogen SE, Lipsitz S, et al. Lag time in an incident reporting system at a university hospital in Japan. Qual Saf Health Care. 2007; 16(2): 101e4. http://dx.doi.org/10.1136/qshc. 2006.019851

[21] Regenbogen SE, Hirose M, Imanaka Y, et al. A comparative analysis of incident reporting lag times in academic medical centers in Japan and the US. Qual Saf Health Care. 2010; 19(6): e10. http://dx.doi.org/10.1136/qshc. 2008.029215

[22] Hirose M, Imanaka Y, Fukuda H, et al. A nationwide survey on patient safety culture in Japan. Paper presented at ISQua's 30th International Conference. Edinburgh, Scotland, UK; 2013 October 13-16.

[23] Hirose M. Report of a study on development and verification of a visual indicator for patient safety culture: Grants-in-Aid for scientific Research (challenging exploratory research) (Japanese) Available from: https ://kaken.nii.ac.jp/pdf/2013/seika/CFZ19_6 /15201/23659260seika.pdf

[24] Taneda K, Okumura Y, Aizawa Y, et al. Reliability and validity of the Japanese version of the Hospital Survey on Patient Safety Culture. Journal of Japanese Society for Quality and Safety in Healthcare. 2009; 4: 10-24. (Japanese).

[25] Sorra J, Nieva V, Femolaro T, et al. Hospital survey on patient safety culture: 2007 comparative database report. American Healthcare Research and Quality (AHRQ) publication no. 07-002. 2007 April.

[26] Hirose M, Fukuda S, Tsuda Y, et al. A study on health care professional's sense of ethics in Japan. Paper presented at ISPOR's 18th Annual European Conference. Milan, Italy; 2015 Nov 7-11. http://dx.doi.org/10.1016/j.jval.2015.09.1855

[27] Hirose M, Imanaka Y, Ishizaki T, et al. How can we improve the quality of health care in Japan? Learning from JCQHC hospital accreditation. Health Policy. 2003; 66(1): 29-49. http://dx.doi .org/10.1016/S0168-8510(03)00043-5

[28] Hirose M. Briefing report on the Survey of In-Hospital Health Care Safety System in Japan (2010-2011), Health Labour, and Welfare Grant-in-Aid. 2012 May 29 (Japanese). Available from: https ://mhlw-grants.niph.go.jp/niph/search/NID D01. do? resrchNum=201129021A

[29] National University Hospital Council (NUHC) of Japan. For establishment of patient safety system for preventing medical accidents (Proposal). 2001 Spring (Japanese). Available from: http: //www.univ-hosp.net/guide_cat_04_2.shtml

[30] Ministry of Health, Labour and Welfare Review Committee on Health Care Safety Measures. Report on countermeasures for promotion of patient safety management (Japanese). 2002 April 17. Available from: http://www.mhlw.go.jp/topics/2001/0110/ $\mathrm{dl} / \mathrm{tp} 1030-1 \mathrm{c} \cdot \mathrm{pdf}$

[31] Ministry of Health, Labour and Welfare. Mandatory policy of preparation of health care safety management system in hospitals and clinics with beds. Minor revision of Ordinance for Enforcement of the Medical Service Act (Japanese). 2002 October 1. Available from: http://www.mhlw.go.jp/topics/bukyoku/ isei/i-anzen/2/kaisei/

[32] Ministry of Health, Labour and Welfare. Strengthening of establishment of patient safety management in hospitals with advanced technology. Minor revision of Ordinance for Enforcement of the Medical Service Act (Japanese). 2003 April 1. Available from: http://www.mhlw.go.jp/topics/bukyoku/isei/i-a nzen/hourei/dl/021007-1.pdf

[33] Ministry of Health, Labour and Welfare [Changes of health care safety countermeasure fee associated with the revision of medical service act preferential 2006] (Japanese).

[34] Ministry of Health, Labour and Welfare. Outline of Changes of health care safety countermeasure fee associated with the revision of preferential patient safety countermeasure fee. 2010 Apr. (Japanese). Available from: http://www.mhlw.go.jp/bunya/iryouhoken/ iryouhoken $12 / \mathrm{dl} /$ index-002.pdf

[35] Japan Council for Quality Health Care. Notice on initiation of mandatory medical accident reporting. 2004 Sep 21. (Japanese). Available from: http://www.med-safe.jp/pdf/2004.09.21_1.pdf

[36] Ministry of Health, Labour and Welfare. Project of collecting information of reporting medical adverse events (Japanese). Available from: http://www.mhlw.go.jp/topics/bukyoku/isei /i-anzen/jiko/index.html

[37] Ministry of Health, Labour and Welfare. Notice on establishment of Health Care Safety Measures Network (Japanese). Available from: http://www.mhlw.go.jp/topics/bukyoku/isei/i-a nzen/1/torikumi/naiyou/hiyari/tuuchi/1.html

[38] Ministry of Health, Labour and Welfare. Guidelines for the creation of program of patient safety seminar (Japanese). 2007 Mar. Available from: http://www.mhlw.go.jp/topics/bukyoku/is ei/i-anzen/houkoku/dl/070330-2.pdf

[39] Ministry of Health, Labour and Welfare. Overview of the fifth revision of medical service act (Japanese). 2006 Apr. Available from: ht tp://www.mhlw.go.jp/shingi/2007/11/dl/s1105-2b.pdf

[40] Eisenberg JM, Foster NE, Meyer G, et al. Federal efforts to improve quality of care: the quality interagency coordination task force (QuIC). Joint Commission Journal on Quality Improvement. 2001; 27(2): 93-100. PMid: 11221014.

[41] Bagian JP, Gosbee JW. Developing a culture of patient safety at the VA. Ambul Outreach. 2000; 25-9. PMid: 11067444.

[42] Mears D, White SV. Bagian on patient safety initiatives. Interview by Deborah Mears. J Healthc Qual. 2002; 24(1): 15-16. http://dx.doi.org/10.1097/01445442-200201000-00004

[43] Heget JR, Bagian JP, Lee CZ, et al. System innovation: Veterans health administration national center for patient safety. Jt Comm J Qual Improv. 2002; 28(12): 660-5. PMid: 12481600.

[44] Stalhandske E, Bagian JP, Gosbee J. Department of Veterans Affairs patient safety program. Am J Infect Control. 2002; 30(5): 296-302. http://dx.doi.org/10.1067/mic. 2002.127388

[45] Teleki SS, Damberg CL, Sorbero ME, et al. Training a patient safety work force: the patient safety improvement corps. Health Serv Res. 2009; 44(2): 701-16. http://dx.doi.org/10.1111/j.1475-6 $773.2008 .00927 . x$

[46] National Aeronautics and Space Administration. NASA and VA roll out new reporting system for patient safety. 2002 Apr 5. Available from: http://www.nasa.gov/centers/ames/news/rel eases/2002/02_40AR.html

[47] Hirose M. An overview of patient safety activities at Kyoto University and in Japan. Iryou to Shakai (Health Care and Society). 2006; 16(1): 33-53. http://dx.doi.org/10.4091/iken.16.33

[48] Gandhi TK, Graydon-Baker E, Barnes JN, et al. Creating an integrated patient safety team. Jt Comm J Qual Saf. 2003; 29(8): 383-90. PMid: 12953602.

[49] Campbell WB. Surgical morbidity and mortality meetings. Annals of the Royal College of Surgeons of England. 1988; 70(6): 363-5. Available from: http://www.ncbi.nlm.nih.gov/pmc/article s/PMC2498614/. PMid: 3207327. 
[50] Gawande AA. Complications: a surgeon's notes on an imperfect science. London: Profile; 2002. 47-74 p.

[51] Orlander JD, Barber TW, Fincke BG. The morbidity and mortality conference: the delicate nature of learning from error. Academic Medicine. 2002; 77(10): 1001-6. http://dx.doi.org/10.1097 /00001888-200210000-00011

[52] Ministry of Health and Welfare. Medical practitioners act (Japanese). 1948 Jul 30. Available from: http://law.e-gov.go.jp/htmld ata/S23/S23HO201.html

[53] Common Achievement Test Organization. Overview of the organization and the background of implementation of CBT and OSCE (Japanese). Available from: http://www.cato.umin.jp/02/01 02keii.htm and http://www. cato.umin.jp/05/0101kyouyo u_gaiyou.html

[54] Sakurai H. Japan Medical Association's fundamental Continuous Medical Education policy. Igaku Kyouiku (Medical Education). 2004; 35(3): 191-194. (Japanese).

[55] Iinuma M. Japan Medical Association's Continuous Medical Education Curriculum 2009. Journal of Japan Pediatric Association. 2009; 38: 15-19. (Japanese).

[56] Gary NE, Sabo MM, Shafron ML, et al. Graduates of foreign medical schools: progression to certification by the Educational Commission for Foreign Medical Graduates. Acad Med. 1997; 72(1): 17-22. PMid: 9008563.

[57] Melnick DE. From defending the walls to improving global medical education: fifty years of collaboration between the ECFMG and the NBME. Acad Med. 2006; 81(12) Suppl: S30-5. http: //dx.doi.org/10.1097/01. ACM.0000243462.05719.e1

[58] Whelan GP, Boulet JR, McKinley DW, et al. Scoring standardized patient examinations: lessons learned from the development and administration of the ECFMG clinical skills assessment (CSA). Med
Teach. 2005; 27(3): 200-6. http://dx.doi.org/10.1080/014 21590500126296

[59] Hallock JA, Kostis JB. Celebrating 50 years of experience: an ECFMG perspective. Acad Med. 2006; 81(12) Suppl: S7-S16. http: //dx.doi.org/10.1097/01. ACM.0000243344.55996.1e

[60] McKinley DW, Hess BJ, Boulet JR, et al. Examining changes in certification/licensure requirements and the international medical graduate examinee pool. Adv Health Sci Educ Theory Pract. 2014; 19(1): 19-28. http://dx.doi.org/10.1007/s10459-013-9456-6

[61] Organisation for Economic Co-operation and Development. Health at a Glance: OECD Indicators. 2010. Available from: http://www . oecd.org/els/health-systems/49105858.pdf

[62] Ministry of Health, Labour and Welfare. Population survey report: vital statistics. 2009 (Japanese). Available from: http://www . mhlw .go.jp/toukei/saikin/hw/iryosd/09/dl/02.pdf

[63] Ministry of Health, Labour and Welfare [Changes of health care safety countermeasure fee associated with the revision of medical service act preferential 2006] (Japanese). Available from: http://www.statista.com/statistics/185843/num ber-of-all-hospitals-in-the-us-since-2001/

[64] Kodate N. Events, politics and patterns of policy-making: impact of Major incidents on health sector regulatory reforms in the UK and Japan. Social Policy and Administration. 2012; 46(3): 280-301. http://dx.doi.org/10.1111/j.1467-9515.2011.00814.x

[65] World Health Organization. The world health report 2000: health systems: improving performance. Geneva: World Health Organization.

[66] Inokuchi K. Visiting old, learn new: from the viewpoint of clinical medicine and laboratory medicine (Wagakuni Kindai Igaku no Onkochishin- Byouin Igaku to Jikkennshitu Igaku no Tachibakara). JMAJ. 1997; 117: 971-983. (Japanese). 